\title{
Should Canadian physicians support parallel private health care?
}

\author{
Sacha Bhatia, Adam Natsheh
}

B See related articles pages 896 and 898

$\mathrm{D}$ elegates at the CMA's General Council meeting in August voted by a margin of almost 2:1 in favour of a resolution supporting access to private insurance to cover medically necessary services that the public system fails to deliver in a timely way. This decision marks a significant change in policy from just a decade years ago, when delegates at the 1996 General Council meeting defeated a similar motion. ${ }^{1}$

During this debate at this year's General Council, many of the arguments for "private" medicine centred on stories from physicians about patients who suffered while they waited for care. Although these stories are important, the lack of evidence-based discussion left the most important questions unanswered: Will private medicine actually improve access to care for patients, and what will the consequences of privately insured care be for the public system?

Proponents of increased private financing and delivery of health services say that parallel private insurance will shorten wait times for care. The available evidence does not bear this out. In fact, in countries where there exists a blend of private and public medicine, the problem of wait times still exists, and in areas with high rates of private insurance wait times in the public sector are increased..$^{2-4}$ More importantly, patients in a private system do not live longer or have a better quality of life than those in a public system, and may actually suffer higher rates of illness and death..$^{5-7}$

Although the recent Supreme Court Chaoulli decision in has reignited the debate, this case reflected the state of the Quebec health care system in 1997, immediately following deep cuts to federal and provincial health care funding. Since that time, with federal budgets in surplus, there has been a substantial commitment to reinvestment in health care, and across the country steps are being taken to improve quality of care and reduce wait times within the public system. For example, the Cardiac Care Network in Ontario and the Western Canadian Wait Time registry were cited by the Kirby commission as models to be emulated. In Ontario, $92 \%$ of patients receive elective cardiac surgery within the maximum recommended wait times, ${ }^{8}$ up from $77 \%$ in 2002. In Saskatchewan, $82 \%$ of surgeries take place within 6 months. Moreover, these improvements have been made without the benefit of the $\$ 41$ billion that the federal government has committed to health care over the next 10 years; we can therefore expect more improvement in the near future.

That being said, more than money is needed to solve the issue of wait times in health care. What is needed is a commitment by governments and the health care professions to properly define who should be on a waiting list, accurately track patient movement through the system, introduce a pan-Canadian electronic health record, adopt a systems-oriented approach to resolving backlogs, provide the public with outcome-based information, invest in health human resources, provide incentives for interdisciplinary care, and implement the best clinical practices based on international experience.

The dangers of allowing the growth of the private health care sector in Canada simply do not justify the potential increased access to care for a few wealthy Canadians. Sick patients who cannot afford to pay for care would suffer through longer waits as less critically ill patients with private insurance jump the queue. Medicare will be further weakened as health care providers spend more time away from the public system delivering private care. Overall health care costs will increase because of the loss of our single-payer system, and as corporations begin to shoulder the cost of private insurance for workers, Canada's competitive advantage over the United States will disappear.

But most of all, we will have compromised one of the fundamental values that our Canadian society is built on: equality. Although they may not share the same political perspectives, it is difficult to ignore the fact that both Senator Kirby and Mr. Romanow shared one key conclusion based upon their extensive review of all the empirical evidence: "allowing a parallel private system will...make public waiting lines worse" (Senator Kirby), and "private facilities may improve waiting for the select few" but will make them "worse for the many" (Mr. Romanow). ${ }^{10}$

At their recent conference, CMA delegates also passed a motion stating that access to care should be based on need, not on ability to pay. However, this position is impossible to reconcile with endorsing a system that would allow wealthier patients to buy their way to the front of the line. This is not to say that no one would benefit from increasing privatization, but those beneficiaries would be those who could afford private health care, and those who provide it, including doctors and insurance companies.

The downfall for physicians in all this can already be seen. An editorial in the Toronto Star just after the CMA General Council called the CMA "myopic" and suggested that Canadian physicians were acting in their self interest by voting for the private system. ${ }^{11}$ This view is not a new 
